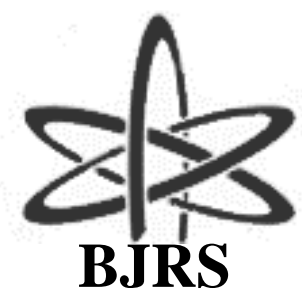

\author{
BRAZILIAN JOURNAL \\ $\mathrm{OF}$ \\ RADIATION SCIENCES \\ 07 (2019) 01-13
}

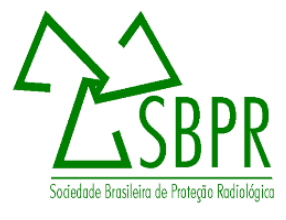

\title{
A perspectiva do estudante da Escola SESC de Ensino Médio a respeito da geração de energia núcleo-elétrica
}

\author{
Souza $^{a}$ J. S. S. S., Jeronimo ${ }^{a}$ V. M. M., Pedrozo ${ }^{a}$ M. G. L., Quadros ${ }^{a}$ B. B., Silva ${ }^{a}$ J. P. \\ S., Silva ${ }^{\mathrm{a}}$ L. Z. D., Teixeira ${ }^{\mathrm{a}}$ C. G., Gonçalves $\mathrm{Jr}^{\mathrm{a}}$ M. A. \\ ${ }^{a}$ Departamento de Ciências da Natureza/Escola SESC de Ensino Médio, 22775-004, Rio de Janeiro-RJ, Brasil \\ $<j u j u . s a n t i a g o .57 @ g m a i l . c o m>$
}

\section{RESUMO}

O trabalho busca compreender o ponto de vista dos jovens estudantes do ensino médio sobre a geração de energia núcleo-elétrica no Brasil. Foi realizada uma pesquisa a partir de um questionário com alunos da Escola Sesc de Ensino Médio, indicativo de tal perspectiva. $O$ entendimento, por sua vez, dá-se a partir da análise de influências educacional, social e familiar. Para melhor compreensão, divide-se os alunos em diferentes momentos do ensino médio, de acordo com o acesso que os mesmos tiveram a um conhecimento científico. No estudo, notase que a aceitação acerca da geração de energia nuclear em território brasileiro ocorre de maneira gradual ao longo dos anos na escola.

Palavras-chave: geração de energia, energia nuclear, ensino de ciências.

ABSTRACT

This present paper seeks to understand the high school students point of view about nuclear power generation in Brazil. It was conducted a research by a questionnaire with Escola Sesc de Ensino Médio students, indicative of such perspective. The analysis, which in turn, took place from educational, social and familiar influences on forming the opinion. To better understanding, the answers are introduced at different stages of high school, according to the access that they had to a scientific knowledge. The study suggests that the acceptance about the nuclear power generation in Brazilian territory can occur gradually over the years at school, growing as long as the student have access to the theme in classroom.

Keywords: power generation, nuclear energy, science teaching. 


\section{INTRODUÇÃO}

Os estudos sobre a natureza radioativa do átomo, realizados desde a virada do século XIX para o XX por grandes nomes da física moderna como Ernest Rutherford, Marie Curie, Joseph Thomson e Antoine Becquerel, e a descoberta da fissão nuclear, em 1934, por Enrico Fermi, significaram um grande impulso nos estudos da energia nuclear. Tais avanços foram fundamentais para que, em 1938, Otto Hahn e Fritz Strassmann obtivessem sucesso na primeira fissão nuclear do urânio na prática. O grande feito foi explicado por Lise Meitner e Otto Frisch. Diante desse significativo avanço na compreensão da energia nuclear, o governo nazista, logo em 1939, iniciou o projeto de energia nuclear alemão [1]. O objetivo era desenvolver armas nucleares para a recém iniciada Segunda Guerra Mundial.

A possibilidade da Alemanha desenvolver a arma nuclear, no entanto, levou os físicos Albert Einstein e Leo Szilard a assinarem uma carta enviada ao presidente dos EUA na época, Franklin D. Roosevelt. O conteúdo da carta comunicava o líder americano sobre o possível poder de uma arma nuclear e o perigo que a fabricação desta pela Alemanha significaria. O conhecimento sobre a situação do uso da tecnologia nuclear pelo regime nazista levou o presidente Roosevelt, então, a considerar a possibilidade de um projeto nuclear americano. Em 1942, o primeiro reator nuclear foi construído em Chicago, e em seguida a primeira reação em cadeia, dando início ao programa nuclear dos EUA: o Projeto Manhattan. A iniciativa foi conduzida pelo general Leslie Groves e pelo físico Robert Oppenheimer, diretor-geral.

O primeiro resultado do projeto veio em 1945 quando a primeira bomba atômica, batizada de Trinity, foi testada com sucesso no deserto do Novo México. O sucesso do teste impulsionou a utilização da arma na guerra. Assim, com outras duas bombas, a Little Boy e a Fat Man, os EUA atacaram as cidades de Hiroshima e Nagasaki, no Japão - o único país do Eixo ainda beligerante -, deixando mais de 200 mil civis mortos [2].

O fim da Segunda Guerra Mundial consolidou os EUA como a maior potência econômica e militar do mundo, e se mantiveram durante toda segunda metade da década de 40 como o único país a ter a tecnologia nuclear para fins bélicos, pondo-se à frente da União das Repúblicas Socialistas Soviéticas na corrida armamentista. Entretanto, em 29 de agosto de 1949, a URSS se tornou o 
segundo país a detonar um dispositivo nuclear, alcançando o status bélico dos EUA e introduzindo a tecnologia nuclear à Guerra Fria.

Nos anos seguintes a política armamentista soviética teve grande crescimento, adquirindo a bomba de hidrogênio, em 1953, apenas nove meses após os EUA, mostrando-se uma ameaça à hegemonia armamentista norte-americana.

A partir de então, a tecnologia nuclear teve seu foco na produção de energia elétrica, disseminando-se pelas potências da época, então, inúmeras usinas nucleares. Com o crescimento do número usinas (mais de 400 em operação em todo o mundo atualmente) e, consequentemente, da capacidade de produção, a população passou a temer também possíveis desastres em centrais nucleares, sentimento que ficou evidente principalmente diante dos acidentes nucleares de Three Mile Island, em 1979; Chernobyl, em 1986; e Fukushima, em 2011.

Desse modo, o medo de armas e desastres nucleares foi latente no século passado. A geração que viveu o período de Guerra Fria teve, e tem até os dias atuais, seu imaginário permeado pela insegurança decorrente ao belicismo e desconhecimento frente a novas tecnologias, que se parecem ameaçadoras em decorrência de desastres nucleares.

O contexto histórico apresentado justifica a mentalidade que forjou a opinião pública, essencialmente negativa, em torno da energia nuclear ao longo da segunda metade do século XX. Por outro lado, não se tem informações mais precisas sobre a opinião daqueles que se distanciam temporalmente do período de extrema tensão envolvendo a energia nuclear.

O presente trabalho busca compreender a perspectiva da geração nascida no século XXI sobre a energia nuclear, com ênfase nos jovens brasileiros. Em especial, os que cursam atualmente o ensino médio, período em que o contato com o tema é desenvolvido segundo os Parâmetros Curriculares Nacionais (PCN) do ensino médio [3]. Para além, tal grupo é grande indicativo de como as políticas e pesquisas científicas em relação à energia nuclear tendem a caminhar e a serem aceitas pela população. Pode ainda auxiliar os professores no sentido de ajustar conteúdos e pavimentar com mais qualidade os itinerários formativos dos estudantes.

Destarte, a pesquisa aqui presente tem por objetivo o estudo e a compreensão da perspectiva dos estudantes da Escola Sesc de Ensino Médio a respeito da geração de energia núcleo-elétrica em território nacional, levando em consideração fatores geradores de opinião, como o parecer familiar sobre o tema, mídias e o ensino formal das escolas, dá base ao pensamento científico formal. E, 
dessa forma, compreender os motivos que levam os estudantes a pensarem de determinado modo, identificando possíveis falhas que impedem a formação do pensamento crítico acerca do tema tratado. Assim, visa ao desenvolvimento de uma pesquisa de caráter exploratório com alunos da Escola Sesc de Ensino médio para compreender seu posicionamento a respeito da temática além de possuir aspectos explicativos, concernentes ao esclarecimento de fenômenos identificados no processo de exploração.

\section{MATERIAIS E MÉTODOS}

A pesquisa foi conduzida empregando-se o método estatístico, que caracteriza estudos que se preocupam com a descrição quantitativa de características de um determinado grupo da sociedade [4]. Os dados foram obtidos por meio do preenchimento de um questionário online, respondido por alunos de ensino médio, com o objetivo de fazer um levantamento acerca do fenômeno de interesse. Classifica-se então como uma pesquisa de campo [5].

O questionário foi elaborado e respondido por meio da plataforma Forms, da Google. A pesquisa de opinião foi feita no ano de 2017 com alunos da Escola Sesc de Ensino Médio, uma escola residência localizada na cidade do Rio de Janeiro, que abriga estudantes de todos os estados da federação e diferentes condições socioeconômicas. Todos os alunos da Escola receberam o link de acesso ao questionário por e-mail e foram instruídos pela equipe docente a preenchê-lo. Os interrogados forneceram algumas de suas informações básicas (nome, naturalidade, idade e nível de escolaridade) e responderam a 20 perguntas.

\section{RESULTADOS E DISCUSSÃO}

A partir das perguntas feitas por meio do questionário, foram obtidas informações essenciais para a compreensão da perspectiva do estudante, que aqui são discutidas. No total, dos 495 alunos da escola, 396 responderam ao formulário, sendo 150 estudantes da primeira série, 159 da segunda e 87 da terceira. Esse grupo corresponde a uma pequena amostra dos 51,3 milhões de brasileiros jovens, segundo o Censo de 2010, com erro amostral de aproximadamente 5\% e nível de confiança de $95 \%$. [6] 
Ao analisarmos a pergunta "Qual das opções abaixo representa a sua opinião a respeito da geração e utilização de energia nuclear em território brasileiro?” percebemos que a maioria (62,3\%) se coloca como a favor, pois enxerga mais benefícios do que malefícios, enquanto uma minoria $(37,7 \%)$ é contra, uma vez que considera que os riscos são maiores que os benefícios. Dessa forma, depreendemos que mesmo havendo maioria a favor, há uma minoria muito expressiva, mostrando, no geral, relutância em relação à geração de energia nuclear em território brasileiro. É importante compreender, portanto, que motivos levam os contrários a pensar desse modo, uma vez que representam grande parcela do grupo amostral.

Deve-se ressaltar a disparidade entre os entrevistados de acordo com sua série no ensino médio. Nota-se que a primeira série possui $54 \%$ de alunos a favor e $46 \%$, contra, representando o grupo mais polarizado em relação à temática. Apesar da possibilidade de acesso a informações sobre energia nuclear desses estudantes numa etapa anterior da escolaridade regular, no ensino fundamental, é provável que estejam mais fortemente sujeitos a uma assimilação de preceitos equivocados e estereotipados sobre a energia nuclear.

A comparação entre os resultados obtidos a partir das perguntas feitas no questionário para cada série requer uma análise estatística mais criteriosa. Entretanto, com a base numa avaliação pura das porcentagens, verifica-se uma indicação de aumento discreto de quem é favor na segunda série em relação à primeira (de 54\% para $61 \%$ ) e uma redução de quem é contra (de $46 \%$ para $39 \%$ ). A ligeira variação dos percentuais é justificável. Por mais que a segunda série ainda não tivesse tido aulas específicas sobre energia nuclear, esses estudantes estão imersos, há mais tempo que os da primeira série, em um ambiente escolar que se propõe a desmistificar preceitos e iniciar cientificamente os alunos. No campus, os alunos têm maior proximidade com a temática a partir de conversas, comentários pertinentes dos professores na sala de aula e, sobretudo, da iniciação científica, que aguça o olhar investigativo levando o estudante a encarar as situações e os postulados sociais de modo mais crítico, procurando entender a realidade por meio da pesquisa.

Em contraponto, a terceira série apresenta uma maioria muito significativa de alunos que são a favor da geração de energia nuclear em território brasileiro (81\%), enquanto $19 \%$ são contra. O resultado é muito provavelmente devido a uma ação coordenada do corpo docente com o objetivo de abordar o tema de forma mais apropriada. Houve, no ano de 2016, uma palestra com uma pesquisadora do Instituto Radioproteção e Dosimetria, IRD, fruto de uma parceria entre esse centro 
de pesquisa e a Escola. No encontro foram apresentados conceitos e evidências que contribuíram para a compreensão de fenômenos físicos e biológicos e que ajudaram a desmistificar algumas concepções equivocadas. Foram discutidas questões relacionadas ao acidente radiológico de Goiânia e à maneira como ocorre a geração de energia elétrica em usinas nucleares.

No primeiro semestre de 2017, o tema voltou a ser trabalhado pela disciplina de geografia, que apresentou aspectos sociais relativos à produção de energia nuclear, indicando características relevantes para a área de Ciências Humanas. O tema também foi abordado nas aulas de química, fundamentais para o entendimento da utilização da energia nuclear na medicina e em outras áreas. A pergunta "A temática da energia nuclear foi apresentada a você no ensino médio?" reflete o acesso gradual a esse conhecimento, considerando que a apresentação formal só foi feita à terceira série. Para essa pergunta, 58,5\% responderam que não (entre os quais 75,3\% da primeira série, $65 \%$ da segunda série e $15,6 \%$ da terceira série), em contraste com 41,5\% que responderam sim (24,7\% da primeira série, $35 \%$ da segunda e $84,4 \%$ da terceira).

Tabela 1: Se sim, de que forma você teve contato com ela?

\begin{tabular}{ccccc}
\hline & \multicolumn{4}{c}{ Ano escolar } \\
\cline { 2 - 4 } & $\mathbf{1}^{\circ}$ ano & $\mathbf{2}^{\circ}$ ano & $\mathbf{3}^{\circ}$ ano & Total \\
\hline $\begin{array}{c}\text { Currículo } \\
\text { Hackeado } \\
\text { Currículo }\end{array}$ & 0 & 0 & 0 & $0(0 \%)$ \\
Comum & 31 & 26 & 48 & $105(53,6 \%)$ \\
Palestras & 4 & 20 & 22 & $46(23,5 \%)$ \\
Grupos & 12 & 21 & 5 & $38(19,4 \%)$ \\
Informais de & & & & \\
Debate & 4 & 1 & 0 & $5(2,6 \%)$ \\
Comitês & & & & \\
\hline
\end{tabular}

Já a pergunta seguinte: "Se sim, de que forma você teve contato com ela?", apenas $20,7 \%$ dos estudantes da primeira série reconhece ter tido acesso ao tema através do currículo regular comum. 
De fato, em função da menor ênfase dada à energia nuclear nessa etapa escolar, o resultado já era esperado. Por outro lado, o dado evidencia a abordagem e tentativa de inserção de algumas ideias relativas ao conteúdo por parte dos professores desde o início do ensino médio.

Já na segunda série, 35\% dizem ter tido o contato. E, quando perguntados de que forma, dividem-se em currículo comum (47,2\%), grupos informais de debates $(38,2 \%)$ e palestras $(36,3 \%)$, lembrando que mais de uma alternativa poderia ser assinalada. Demonstra-se, portanto, o papel do ambiente escolar de gerar discussões sobre o assunto, seja por meio de palestras ou debates que partem de iniciativas discentes e docentes, na sala de aula.

Por sua vez, $84,4 \%$ dos jovens da terceira série afirmaram ter tido o contato com a temática, em contraste com 15,6\%, que afirmaram que não o tiveram. Apesar do pequeno percentual, os professores devem ficar atentos em relação ao grupo que não reconhece ou não aprendeu o conteúdo de maneira satisfatória com o objetivo de melhorar a abordagem. Dos 84,4\%, 68,5\% dizem ter tido o contato pelo currículo comum e 31,4\% em palestras. A palestra mais significativa sobre energia nuclear foi à ministrada pela pesquisadora Arlene Alves, já referida neste artigo anteriormente.

Já a pergunta "O quão informado você se considera sobre energia nuclear?" foi analisada a partir de uma escala que varia de 1 a 5 , em que 1 traduz-se como "nada informado" e 5 como "muito informado". A maioria dos entrevistados encontra-se no espectro 2 e 3, com 31,8\% e 30,5\%, respectivamente. As respostas referentes à primeira série concentram-se nos espectros 1,2 e 3 , de modo bem distribuído entre eles (30\% nos dois primeiros e 32\% no terceiro). Já a segunda série encontra-se, majoritariamente, em 1 e 2 (31,8\% e 35,7\% respectivamente). A terceira série, por sua vez tem maioria no ponto 3 do espectro $(47 \%)$. 
Tabela 2: Por qual(is) meio(s) você tem contato com a temática da energia nuclear?

\begin{tabular}{ccccc}
\hline & \multicolumn{4}{c}{ Ano escolar } \\
\cline { 2 - 5 } & $\mathbf{1}^{\circ}$ ano & $\mathbf{2}^{\circ}$ ano & $\mathbf{3}^{\circ}$ ano & Total \\
\hline $\begin{array}{c}\text { Mídias, como } \\
\text { jornais, revistas e } \\
\text { televisão }\end{array}$ & 98 & 108 & 54 & $261(66,9 \%)$ \\
Escola & 57 & 57 & & \\
Redes Sociais & 57 & 59 & 73 & $187(47,9 \%)$ \\
Senso comum & 39 & 62 & 36 & $152(39 \%)$ \\
Outros & 28 & 28 & 14 & $131(33,6 \%)$ \\
Nenhum & 7 & 8 & 0 & $15(3,8 \%)$ \\
\hline
\end{tabular}

Apreende-se, por meio da tabela 2, que a maioria dos entrevistados tem contato com a temática por meio de mídias, como jornais, revistas e televisão $(66,9 \%)$, demonstrando informalidade de acesso ao conteúdo. Ao tratar da energia nuclear, veicula tendências únicas, de aspecto sensacionalista e de pouco rigor científico. Segundo Sérgio Vilas Boas, "Por ser um negócio, não se pode esperar que a mídia divulgue ciência por motivos altruístas. Para ser veiculada pela mídia, a ciência tem que ser capaz de despertar interesse, manter a atenção do leitor, ouvinte ou telespectador até o fim do artigo ou programa, e ser bem entendida pelo grande público" [7]. Desse modo, divulgar acidentes em usinas e o uso de energia nuclear para fins bélicos, apresenta-se como conveniente, uma vez que tange um dos instintos mais primitivos do ser humano: o medo.

Outro meio de acesso é através da escola (47,9\% dos entrevistados), onde é possível obter o conhecimento formal sobre o tema. Ênfase na terceira série, em que $88 \%$ afirma ter o contato. Verifica-se, portanto, um indicativo de ampliação do acesso ao conhecimento a partir de fontes mais confiáveis em função da permanência na escola e avanço nas séries regulares.

Por sua vez, $39 \%$ tem o contato por meio das redes sociais, que pode tanto ser um espaço de disseminação de senso comum quanto de conteúdo científico independente. Portanto, é dual. 
Tabela 3: Quando você ouve o termo "energia nuclear", o que primeiro vem a sua mente?

\begin{tabular}{ccccc}
\hline & \multicolumn{4}{c}{ Ano escolar } \\
\cline { 2 - 5 } & $\mathbf{1}^{\circ}$ ano & $\mathbf{2}^{\circ}$ ano & $\mathbf{3}^{\circ}$ ano & Total \\
\hline $\begin{array}{c}\text { Acidentes em } \\
\text { usinas }\end{array}$ & 18 & 16 & 15 & $49(12,6 \%)$ \\
Armas nucleares, & 46 & 49 & 5 & $100(25,6 \%)$ \\
como bombas & 1 & 0 & 0 & $1(0,3 \%)$ \\
Cura do câncer & 85 & 85 & 58 & $228(58,5 \%)$ \\
$\begin{array}{c}\text { Geração de } \\
\text { energia elétrica } \\
\text { Mutação gênica }\end{array}$ & 0 & 7 & 4 & $11(2,8 \%)$ \\
Esterilização de & & & & $1(0,3 \%)$ \\
Alimentos & 0 & 0 & 1 & \\
\hline
\end{tabular}

A Tabela 3 apresenta os resultados da pergunta "Quando você ouve o termo 'energia nuclear', o que primeiro vem a sua mente?”. Pode-se observar que mais da metade da amostragem (58,5\%) relacionou o termo à geração de energia elétrica, associando a fins pacíficos. Indica, portanto, um pensamento difundido de cunho mais científico e compreensivo em relação à aplicação da energia nuclear no cotidiano do brasileiro. Ressalva à terceira série, com valores - em média - 15\% mais altos.

Em segundo lugar, uma parte significativa, cerca de um quarto, remete o termo à utilização para fins bélicos. A relação está presente entre $31 \%$ dos estudantes da primeira e da segunda série. Já entre os estudantes da terceira série, apenas 5\% apontam relação entre energia nuclear e fins bélicos. Esse resultado indica que o contato formal com o tema a partir de informações provenientes de fontes confiáveis pode desmistificar o uso da energia nuclear e sugere avanço no que tange ao entendimento sobre o tema.

Em terceiro lugar, a opção "acidentes em usinas" têm expressiva participação, demonstrando ainda um pensamento muito recorrente devido à alta midialização e desenvolvimento de estudos focados unicamente no aspecto histórico desastroso da geração de energia nucleoelétrica mundial. 
Com a pergunta "Como você se sente em relação à presença de usinas de geração de energia nuclear em território brasileiro?" foi possível observar que a maioria dos entrevistados $(48,7 \%)$ possui posição incerta em relação a presença de usinas nucleares no território brasileiro, por posicionarem-se no ponto 3 de uma escala de 1 a 5 . Porém, apesar da incerteza, os alunos tendem a estar mais seguros do que inseguros, uma vez que 15,2\% posicionaram-se em 1 ou 2, enquanto $36,1 \%$ posicionam-se em 4 ou 5 , em uma escala em que 1 representa muito inseguro e 5 muito seguro.

O sentimento de incerteza não se dá apenas em relação às usinas nucleares, uma vez que, quando questionados a respeito da associação do termo energia nuclear com o termo energia confiável, a variação da disposição dos entrevistados na escala de 1 a 5, sendo 1 nada confiável e 5 muito confiável, os alunos continuam se concentrando na posição 3 com 33,3\%, apesar dos valores terem se distribuído mais igualitariamente em 2 e 4 (23,1\% e 26,9\%, respectivamente).

As respostas da pergunta sobre a importância da energia nuclear para a matriz energética brasileira variam de "pouco importante" para "muito importante". Em que, a maioria dos entrevistados concentra suas respostas no centro do espectro $(31,8 \%)$, o que poderia ser entendido como "relativamente importante". Nota-se, portanto, resistência dos alunos sobre a utilização de tal tecnologia para gerar energia. Contudo, o restante dos alunos, em sua maioria, tende a reconhecer a importância, somando 43,3\% dos estudantes em relação ao polo "importante" (espectro 4 e 5). Representa, então, uma predisposição à aceitação da energia nuclear como uma fonte importante de geração de energia para o país.

A pergunta "O quanto você acredita que uma usina nuclear pode poluir o meio ambiente" busca compreender a visão do entrevistado sobre o impacto ambiental provocado pelas centrais nucleares em comparação com outras fontes, o que influencia diretamente na percepção do estudante sobre a geração de energia núcleo-elétrica. Em uma escala de 1 a 5 , sendo 1 polui nada e 5 polui muito, os alunos encontram-se, em maioria, no espectro 4, seguido do 3 e 5 . Ao analisar por série, o ano que se difere mais da média é o terceiro, que tem maioria no espectro 2 , com $38,6 \%$, seguido do 3 , com $22,9 \%$. Há, portanto, por parte da terceira série, a ciência de que uma usina nuclear não polui muito se comparada com outras fontes de geração de energia, o que possivelmente é uma motivação para a opinião mais favorável desse grupo. 
Ao serem questionados sobre a opinião da família do estudante a respeito da geração de energia nuclear em território brasileiro, 17,4\% dizem que a família é a favor e 19,7\%, contra. Já em 62,8\% dos casos, os entrevistados afirmam que a família não conhece o suficiente sobre o assunto para emitir opinião. A pergunta seguinte, por sua vez, "Você acredita que a opinião de seus familiares influenciou na sua opinião sobre o assunto?" tem como respostas $84,6 \%$ que consideram que "não" e $15,4 \%$ que "sim".

A partir dos resultados, é possível depreender que o senso crítico dos jovens dificilmente teria sido desenvolvido durante a sua formação (até o ensino médio) por meio da família, uma vez que $62,9 \%$ dos entrevistados considera que ela não conhece o suficiente para emitir opinião sobre o tema. A visão dos familiares possivelmente está imbuída de preceitos advindos do medo subsequente dos acidentes nucleares, contemporâneos a eles, em que a informação sobre esses se deu por meio de mídias e oralidade de comunicação, que por sua vez tendiam ao sensacionalismo não crítico. O desconhecimento da família influenciou para que a opinião dela não impactasse no posicionamento do jovem (uma vez que $84,8 \%$ dos entrevistados afirmam que a opinião dos familiares não os induziu). Além disso, o distanciamento temporal com acidentes faz com que o medo não os atinja tão diretamente como aos parentes.

\section{CONCLUSÕES}

Pode-se inferir, por meio da investigação realizada, que a perspectiva do jovem à respeito da geração de energia núcleo-elétrica está diretamente ligada ao nível de acesso que o estudante tem à educação formal e informal. Nota-se uma tendência progressiva, ao longo dos três anos do ensino médio, de aumento na aceitação da participação efetiva das centrais nucleares na matriz energética nacional, à medida que se tem acesso ao conhecimento científico.

A opinião favorável sobre usinas nucleares é construída em função de ações pedagógicas que visam a alfabetização e a iniciação científicas dos estudantes e a partir de intervenções pontuais específicas nas diversas disciplinas que integram o currículo regular, sobretudo na terceira série. Sendo assim, a educação é chave no desenvolvimento da sociedade à medida que permite aos 
jovens analisarem as situações de maneira crítica e ampla, garantindo o julgamento individual de base científica.

O estudo apresentado aqui pode ainda subsidiar a escola no sentido de planejar uma abordagem mais consistente e sistemática sobre a geração de energia núcleo-elétrica e aplicações pacíficas das radiações ionizantes, como na área de saúde, indústria, agricultura e pesquisa, desde a primeira série e o respectivo monitoramento regular do aprendizado dos estudantes.

\section{AGRADECIMENTOS}

A todos os professores, em especial aos da equipe de ciências da natureza, funcionários e estudantes da Escola Sesc de Ensino Médio que colaboraram, diretamente ou indiretamente, para a pesquisa. A todos que responderam ao questionário. Aos idealizadores do projeto Pesquisa em Ação, incentivador da pesquisa científica em nível de ensino médio. Ao Grupo de Trabalho IRD_Escolas do Instituto de Radioproteção e Dosimetria pelo suporte, parceria e disseminação das aplicações pacíficas das radiações ionizantes.

\section{REFERÊNCIAS}

[1] POWERS, T. Heisenberg's War: The Secret History of the German Bomb. Boston, MA, Da Capo Press, 2000.

[2] XAVIER, A.; LIMA, A.; VIGNA, C; VEBI, F; BORTOLETO, G; GORAIEB, K; COLLINS, C; BUENO, M. Marcos da História da Radioatividade e Tendências Atuais. Química Nova, v. 30, No.1, p. 83-91, 2007.

[3] MEC - Ministério da Educação. Parâmetros Curriculares Nacionais (Ensino Médio). 2000.

[4] LAKATOS, E. M.; MARCONI, M. A. Fundamentos de metodologia científica. 5. ed. São Paulo: Atlas, 2003.

[5] MORESI, E. Metodologia da Pesquisa. Universidade Católica de Brasília, 2003.

[6] SANTOS, G.E.O. Cálculo amostral: calculadora on-line. Disponível em: <http://www.calculoamostral.vai.la>. Acesso: 16 Jan. 2018. 
[7] BOAS, S. V. Formação e Informação Científica - Jornalismo para Iniciados e Leigos. Ed. Summus Editorial, São Paulo, 2005.

[8] DE ALMEIDA, R. A. Um Estudo Simplificado sobre a Percepção Pública na Área Nuclear: Sugestões para Campanhas Educativas para os Diferentes Segmentos da Sociedade. Dissertação (Mestrado em Engenharia de Reatores). Rio de Janeiro, PPGIEN/CNEN, 2011.

[9] DA COSTA, I; DAS DORES, J; LIRA-DA-SILVA, R. Percepção dos Estudantes do Ensino Médio da Rede Pública de Salvador, Bahia sobre energia nuclear. Disponível em: <http://www.nutes.ufrj.br/abrapec/viiienpec/resumos/R0273-1.pdf> Acesso: 16 Jan. 2018.

[10] LUCENA, E. A. et al. Radiação Ionizante, Energia Nuclear e Proteção Radiológica para a Escola, Brazilian Journal of Radiation Sciences, v. 5, n. 1, 2017. doi: 10.15392/bjrs.v5i1.215.

[11] DA SILVA, F; PESSANHA, P; BOUHID, R. Abordagem do tema controverso Radioatividade/Energia Nuclear em sala de aula no Ensino Médio - Um Estudo de Caso. Disponível em: <http://www.nutes.ufrj.br/abrapec/viiienpec/resumos/R1502-1.pdf> Acesso: 16 Jan. 2018.

[12] MONGELLI, S. T. Geração Núcleo-Elétrica: retrospectiva, situação atual e perspectivas futuras. 2006. Dissertação (Mestrado em Tecnologia Nuclear - Reatores) - Instituto de Pesquisas Energéticas e Nucleares, Universidade de São Paulo, São Paulo, 2006. doi:10.11606/D.85.2006.tde-08062007-151208. Acesso: 07 Jul. 2018.

[13] SANTOS, F; MACHADO, E; ALVES, M; DE PAULA, G; FAMA, F; DA SILVA, A.A; REIS, A. Applications of Ionizing Radiation - Disclosure Is Necessary. Dsiponível em: <https://www.euronuclear.org/events/etrap/etrap2017/pdf/Posters/ETRAP2017-A0045fullpaper.pdf> Acesso: 16 Jan. 2018. 